\title{
PROTESTANTTINEN ETIIKKA JA YLIVIESKALAINEN RAHVAAN MUSIIKKI
}

Joutilaisuuden ja huvittelun vastustus - askeettinen itsekontrolli • suruttomat kurttuset ja heränneet körtit - synnillinen pirunkeuhko ja tanssin pelaaminen • synnittömät marssit, kansanlaulut ja virret - talkootanssien kaksinaismoraali • nurkkatanssin ja yöstelyn sosiaalinen merkitys • herännäisyys ja häämenojen rappio • kuorolaulu sivistävänä vaihtoehtona

Ihmisten arvostusten ja maailmankatsomusten muutosta tarkastellaan usein sosiologian klassikko Max Weberin kuvaaman protestanttisen ihmisen ideaalityypin avulla. Protestanttisen ihmistyypin Suomeen juurtuminen esiteollisesta ajasta nykypäivään tultaessa voidaan nähdä sekä muutoksen osoittajana että sen kuvastajana (Karisto et al. 1984, 167). Protestanttisen etiikan yksilöllisyyden korostus, askeettinen elämäntyyli ja ankara itsekuri toivat uskonnon keskelle arkielämää. Tässä kirjoituksessa lähden siitä, että kansanomaisten uskonnollisten herätysliikkeiden maahamme istuttama protestanttinen etiikka muutti olennaisesti suomalaisten talonpoikien ja työväestön suhdetta soittoon, lauluun ja tanssiin 1800- ja 1900-lukujen vaihteeseen mennessä.

\section{Laskelmoiva suhde aikaan}

Protestanttisen etiikan mukaan raskain synti oli haaskata aikaa. Maallinen työ oli suoritettava moitteettoman tunnontarkasti, sillä työ oli kutsumus: elämästä nauttimista - niin urheilua kuin tanssilava- ja kapakkakäyntejäkin - oli syytä voimallisesti vastustaa. Pietismi kasvatti ihmisiä askeettisuuteen ja sai heidät järjestämään elämänsä metodisesti ja kontrolloimaan itse itseään. (Weber 1980, 113, 116-117, 123-126, 207). Ajan kuluminen haluttiin kääntää kasvavassa määrin hyödyksi ja tehdä kannattavaksi. Mystiset ja askeettiset harjoitukset järjestävät ajan tavoittelemaan autuutta: länsimaisen historian kuluessa tavoite on muuttunut, mutta yhä aika pyritään kumuloimaan hyödylliseen muotoon, jolloin ihmisiin on yhä helpompi käyttää valtaa. (Foucault 1980, 177-184). 
Rahvaan suhde aikaan erosi alunperin porvarin suhteesta aikaan (Frykman et Löfgren 1984, 21-44; Asplund 1983, 95-118). Kuitenkin vähitellen, keskiajalta nykypäivään tultaessa myös talonpoikaisto alkoi yhä suuremmassa määrin mitata jokaista elämän yksityiskohtaa ja punnita erilaisia menettelyvaihtoehtoja tarkasti keskenään. 1700-luvun lopulla kellot olivat jo yleistyneet suomalaisissa talonpoikaistaloissa - enää ei riittänyt, että kyläkokouksen ilmoitettiin alkavan summittaisesti "murkinan jälkeen." (Renvall 1951, 484-485; Aaltonen 1951, 3334.) Aikakäsitykset muuttuivat myös esimerkiksi rautateiden ansiosta: ne edesauttoivat merkittävästi maanlaajuisen yhtenäisen aikanormin, nimittäin ns. Helsingin ajan, yleistymistä 1800-luvun lopulla. Junat mullistivat myős käsityksiä nopeudesta. "Aika ikäänkuin kallistui." (Aaltonen mt. 34-35.)

Luontaistaloudessa elävä ihminen ei nähnyt työtä itsetarkoituksena. Kutsumustyön idea juurtui Suomeen pitkällisen kasvatusprosessin jälkeen. (Karisto et al. 1983, 167). Katolisen tapauskonnollisuuden väistyminen henkilökohtaisen heräämisen tieltä ei sekään tapahtunut uskonpuhdistuksen jälkeen aivan tuossa tuokiossa vaan vasta vähitellen 1700- ja 1800-luvuilla herätysliikkeiden vaikutuksesta. (Renvall 1951, 475-478; Karisto et al. mt. 174). Kimmo Sarjen mukaan $(1982,26)$ Max Weberin kuvaama protestanttinen etiikka vaikutti sittemmin syvästi suomalaisuuteen. Anders Chydenius sanktioi joutilaisuuden yhtä tiukasti kuin Benjamin Franklin konsanaan - viimemainittuahan Weber piti protestanttisen etiikan henkilöitymänä (Weber mt. 42-44). Myös Chydenius tähdensi kirjoituksissaan järkevää ajankäyttöä ja kulutuksen rajoittamista.

Pietismi muokkasi yleistă mielipidettă huvittelua ja ylipäătään hillittömyyttä vastaan kaikilla vaikutusalueillaan. Eräs ns. ankaran pietismin tärkeimmistä tunnusmerkeistä oli tanssin tuomitseminen, ja savolaisvaikutteisen herätyksen myötä heränneet hylkäsivätkin tanssin, jos kohta tuomittaviin asioihin kuului paljon muutakin (Ylikangas 1979, 75-77 ja kuvateksti). Elias Lönnrot kirjoitti vuonna 1835 Helsingfors Morgonbladetiin sarjan herännäisyydenvastaisia kirjoituksia. Hän soimasi heränneitä:

He kieltävät kaiken maailman ilon, eivät siedä tanssia, musiikkia, leikkiä eivätkä lauluja (paitsi hengellisiä), joissa kaikissa mieli toisinaan haluaa virkistyä, jotta se ei vajoaisi surumielisyyteen. Pietistin tuntee jo ulkomuodosta. Silmissä on outo, terveen katseesta poikkeava loiste, nenä muotoutuu ikään kuin terävämmäksi, posket kuihtuvat, puhe menettää voimansa kaikki on lakastuneen näköistä. (Ylikankaan 1979, 221 mukaan).

Nationalistisen sivistyneistön hyökkäyksistä heränneitä vastaan seurasi, että herännäispapit liittyivät yhä tiukemmin yhteen kansallisia herättăjiă vastaan. Herätysliikkeillä oli monessa mielessä myös esipoliittisten liikkeiden merkitystä. (Ylikangas mt. 230-231, 243-250; Suolinna 1977, 119). 


\section{Ylivieska, herätysliikkeet ja musiikki}

Kalajokilaaksosta muodostui 1830-luvulta lähtien myöhäisemmän herännäisyyden tukialue. (Pentikäinen 1981, 643; Ylikangas mt. 33-34, 198-200). Esimerkiksi Ylivieskan herätysvuotena pidetään vuotta 1832 , ja tuona vuonna myös Nivalan heränneitten pieni piiri alkoi säteillä vaikutustaan ulkopuolelleen. Pietismin taloudellinen maailmankatsomus valtasi alaa: ahkeruus, rehellisyys, säästäväisyys ja vaatimattomuus nousivat kunniaan (Vilkuna 1979, esipuhe). Ylivieskalainen lukkari, kirjailija ja valtiopäivämies Pietari Päivärinta on kuvannut sattuvasti, kuinka ulkonainen jumalisuus sekoittui julkiseen jumalattomuuteen ylivieskalaisten elämässä ennen herännäisyyden tuloa, ja miten herännäisyys muutti kaiken (Päivärinta 1885). Naapuripaikkakunnalla Nivalassa ei enää 1900-luvun alussa tarvinnut pitää pappia kahden puolen kiinni, ettei tämä olisi pudonnut ympäripäissään hautaan, kuten oli laita usein edellisen vuosisadan alkupuolella (Vilkuna mt.). Ylivieskan merkittävin juopa kulki tämän vuosisadan alussa heränneitten ja suruttomien eli körttisten ja kurttusten välissä ( $Y$ 9014:13, 14). Lestadiolaisuus levisi Ylivieskaan vähitellen 1860-luvulta lähtien (Pentikäinen mt. 657-660).

Tutustuessani tămän vuosisadan alkuvuosikymmenien ylivieskalaisen rahvaan musiikkiin oli silmiinpistävintä tietynlaisten laulu- ja soittolajien sekä kaiken tanssimisen kuvaaminen synniksi. Esimerkiksi viulunsoittajien sanottiin olleen "vihattuja muilta ihmisiltä ... ku se oli niin hirviän suuri synti ku soitettiin" (Y 9015:56). Raudaskyläläisen viulupelimanni Knut Säilyn (18711948) vaimon kerrotaan "orijailleen" miehensä soittamista naapureiden vuoksi. Viulukortta ja "synnin saparo" eli viulun jousi olisi pitänyt hävittää ja herätä synnistä. Viulunsoiton suhteen tehtiin kuitenkin ero pelaamisen ja soittamisen välillä. Ensin mainittu, tanssisoitto ja tanssikappaleitten soitto kotona, oli syntiä. Sen sijaan marssien, kansanlaulujen, virsien ja muutamien muiden soitteiden ei sanottu olevan syntiă. Myős useat heränneet kävivăt soitattamassa viulupelimanneilla "murheet pois". Joidenkuiden uskovien mielestă kuitenkin kaikki soitto oli syntiä - eräs lestadiolaismies totesi kuunnellessaan harmonia soittavaa poikaa: "Se on niin kaunista että se on varmasti syntiä." (Y 9040:64)

Pelimannit Knut ja Frans (1874-1929) Säily saattoivat soittaa melko hyvin omintunnoin, jos oli joku "rospuuttopäivä, saepäivă ... tai iltasella". Tuolloin Knut saattoi tulla Fransin kotiin viulunsa kanssa ja sanoa, ettă "pelataampa Ransu vähä" (Y 9023:17). Huonolla säällä eivät miesten ulkotyöt olisi kuitenkaan luonnistuneet, joten oli hyvä tilaisuus soittaa.

Usein ihannenormit ja käyttäytyminen saattoivat olla keskenään voimakkaastikin ristiriidassa. Tämä käy hyvin ilmi esimerkiksi seuraavasta Joonas Säilyn kertomuksesta (Y 9023:4). Kertojan isoäiti oli mennyt viime vuosisadan lopulla heinänteon aikana pidettyihin riihitansseihin, lyönyt soittajan viulun kiukaaseen ja saanut myöhemmin ankarasti katua tekoaan. Viulua näet tarvittiin tuohon aikaan vielä kipeästi, esimerkiksi juuri työjuhlissa niitun aikana, vaikka nurkkatanssit normien mukaan olivatkin syntiä. Parhaassa työiässä olevan miehen oli jäätävä niitulta kotiin ja rakennettava uusi viulu, jolloin tähdellistä työaikaa meni hukkaan. 
Rajoittavat normit eivät sallineet harmonikansoittoa ollenkaan: tanssisăvelmien pelaamisen ja laulujen soittamisen vălillä ei tehty eroa kuten oli laita viulun kohdalla. Esimerkiksi Ylivieskan Savelasta kotoisin ollut Jaakko Savela (1891-1967) opetteli harmonikansoiton (monien muiden suomalaisten harmonikansoittajien tapaan) salaa: "Sehän oli ennen hirviän iso synti ko soittaa haitaria. Vainiolla josaki lajosa ne sanovat että ... se kävi opettelemassa." (Y 8428:36) Ajan mittaan suurin osa kyläläisistä kuitenkin tottui Jaakon soittoon, ja näkyvä paheksuminen väheni. Muuten arvostetun, vakavaraisen talonpojan statukselle tanssisoitto ei tehnyt hyväă - Jaakko Savela saatettiin sivuuttaa sanomalla: "Sehän on semmonen pelimanni." (Y9041:63) Neutraalit harmonikan nimitykset harppu ja haitari vaihtelivat tilanteen mukaan. Tansseihin menevällä soittajalla oli "helevetti selässään", ja haluttaessa olla pahansuopia harmonikkaa nimitettiin myös pirunkeuhkoksi. (Y 9027:22; 9042:12.) Suuharppu eli suupeli oli melko yleinen pienten tanssien säestyssoitin, mutta nuoret pojat uskalsivat soittaa sitä lähinnä salaa saunassa. Kanteleen, torvien ja pillien soittamisen ei mainita olleen syntiä, joten myös heränneet saivat niillä musisoida. Yhteistä näille soittimille oli, etteivät ne liittyneet tanssimiseen nimeksikään.

Jos soitto ja viheltäminen olivat pirun kutsumista paikalle, niin tanssi puolestaan tapahtui "hyllyvän helevetin" päällä (vrt. arkkiveisu Ramia piika, ks. Leisiö 1986, 3). Näin on ymmärrettävää, että Jemiina Säilyn äiti näki nuorena tyttönä helvetin portteja muistuttavien maalattujen rinkien avautuvan, kun ystävät olivat viemässä häntä puoliväkisin tansseihin. Silmiinpistävän usein juuri tansseihin- ja häihinmenijöitä vastaan kerrotaan tulleen supranormaalia väkeä. (Y 9031:30; SKSK Ylivieska. Vilpula b)89. 1938; SKSÄ Ylivieska, 117:50. 1971).

Heränneitten ulkoisena tunnusmerkkinä oli körttipuku, jossa tanssimista ei pidetty suotavana (esim. SKSÄ 118:197). Toisaalta esimerkiksi Pietari Päivärinta kuvaa teoksessaan Siveellisyysoloista Pohjanmaalla rahvaan keskuudessa (1905, 16), kuinka heränneet nuoret saattoivat suoraan seuroista mennä johonkin luuvariiheen tanssimaan. Raudaskyläläinen viisunikkari Juho Marjakangas eli Nietti-Jussi (1840-1916) tuo laulussaan Jylhän tanssituvasta esiin körttinutussa tanssimisen - laulussa mainitulla merkillä tarkoitetaan körttinutun liepeitä (SKSÄ 118:32, 1971):

\footnotetext{
Illalla Jylhässä tanssattiin, valssasi vanhat vaaritkin.

Oli siellä vanha Erkkikin, toisen vaatteisa merkkikin.
}

Tanssivat nuoret eivät olleet nähtävästi kokeneet syvällistä omakohtaista heräämistä. Kiellot tulkittiin samaan tapaan kuin 1200- ja 1300-lukujen vaihteen ranskalaisen Montailloun kylän kirkkoherra teki: kun kaikki on kiellettyä, kaikki on sallittua. (Le Roy Ladurie 1978, 171).

Huolimatta tanssinvastaisesta ilmapiiristä nurkkatanssit ja yöstely olivat vielä 1900-luvun alussa Ylivieskan nuorison merkittävimmät toiminta- ja sosiaalistumismuodot (vrt. Sarmela 1969, 233-266). Rippikoulun käynyt nuoriso tanssi riihissä, aitoissa, risteyksissä, kedoilla, silloilla jne. Raudaskylän nuoret 
siirtyivăt usein suoraan kristillisen opiston seuroista sillalle tanssimaan tai hiepannyrryä (piirileikkiă) menemăăn, mită opiston johtaja (vuosilta 1920-1954) herännăispappina ei voinut hyvăksyă. Patriarkaaliseen tyyliin hăn kokosi opiston oppilaista joukon, joka kulki veisaamassa piirinpyörintäpaikkojen reunamilla. Osa nuorista lähti suosiolla kotiin, mutta paatuneemmat tanssijat siirtyivăt vain hiukan syrjemmälle, ja kohta olivat nyrryt tai tanssit taas vauhdissa. (Y 9019:4; 9026:36).

Mahti- ja tanssihăită järjestettiin vuosisadan alun Ylivieskassa enăă mităttömăn văhăn. Kuitenkin Mikko Ylitalon (SKSK E 81) kuvauksen mukaan 1800luvun puolivälin tienoilla talolliset jărjestivăt yleisimmin komeita, monivaiheisia hăită, joissa tanssittiin kiihkeăsti (mt. 6-19). Tămän vuosisadan alkuun mennessä Ylivieskan talolliset olivat lăhes poikkeuksetta liittyneet jompaankumpaan herătysliikkeeseen ja lopettaneet tanssin käytőn hăămenoissaan. Esimerkiksi Raudaskylăssă pidettiin viimeiset talollisen järjestămăt hăăt, joissa tanssittiin, vuonna 1900 - tămän jälkeen tanssihäită järjestivăt etupäässä palkolliset.

Ennen herätysliikkeiden läpimurtoa papit olivat usein elämäntavoiltaan nautiskelevia, eikă tanssi ollut heiltă kiellettyă (Suolahti 1919, 143-144). "Laguslaiset pietistit" eivăt kuitenkaan enăă suvainneet maailmallisia hăămenoja. Maalahden kirkkoherra Wegeliuksen - myöhemmin herännäispappi itsekin tyttärelleen järjestämät häät, joissa tanssittiin ja käyttäydyttiin muutenkin silloisten săätyläistapojen mukaan, ovat tulleet kuuluisiksi. Niissä nuori, Ylivieskassa Laguksen hoivissa herätyksen saanut Karl Gustav von Essen leiskuvasti nuhteli "huolettomasti pilailevia ihmisiä ja puhui antaumuksella ainoasta tarpeellisesta elämässă". (Häggman 1976, 85; ks. myős Ylikangas mt. 32).

Jonas Lagus ei Ylivieskan kappalaisena toimiessaan varmastikaan osallistunut tanssiin häissă, mutta esimerkiksi vuosien 1843-1861 kappalainen Petter Krank (Jaatinen 1981, 622) oli muistitiedon mukaan toista maata (esim. Y 9022:30-31). 1910-luvulla pappien ei ollut enäă tapana tulla hăihin, joissa tanssittiin. Hăătanssi oli liian railakasta uudenaikaiselle papistolle. Morsiuspolskassa ulkona kiertelyyn ja sulhaspolskarinkiin kuului kovaa menoa ja hihkumista, hilikunpolskissa saatiin aikaan riemukas tunnelma yksinkertaisin keinoin, kuten Mari Raudasoja kertoo omissa häissään (1919) tanssitusta rahapolskasta: "Ja siitähän se riemu nousi aina ku ne meni soiton jäläkiin kaikki piirisä. Sitte ku ne yhteen aina tömmäs ja siinä kilijuvat. Siină ilot otettiin ihtestään." (Y 9020:12)

Naisia, joita olisi kutsuttu pelimanneiksi, ei Ylivieskassa ole ollut: katsottiin "että se oli syntistä hommaa se pelaaminen, ettå se rajotti juuri naisten osallistumista vaikkois ollu haluaki" (Y 9041:63). Harmonikkaa ja viulua jonkin verran soittaneista naisista on vain muutamia tietoja. Tyttöä, joka olisi vuosisatamme alun Ylivieskassa ryhtynyt soittamaan vaskipuhaltimia, olisi pidetty "ihan hämmästyttävänä ja poikkeavana ihmisenä" (Y 9041:16). Tuohitorvea tyttösetkin saivat paimenessa soitella. Naiset käyttivät "soitontunteidensa tulkkina" myös kanteletta ja 1920-luvun loppupuolelta lähtien mandoliinia. Lisäksi on yksi maininta naisesta sitran-, toinen sahansoittajana. Naiset soittivat näillä instrumenteilla omaksi ilokseen harvoina vapaina iltahetkinään. Tansseja 
he eivăt säestäneet, eivătkă muutenkaan soittaneet julkisesti. Soitinten rakentaminen tuohitorvesta lăhtien kuului samaten miehille. (Y 9026:7; 8437:6.). Naisille jäi hyvin văhän aikaa tehdä edellä mainittuja asioita. Miehillä kerrotaan olleen enemmän vapaa-aikaa: kun he kerääntyivät iltaisin soittamaan suutaan, "naiset teki paremmin töitä" (Y 8474:71,72).

Musiikkiin liittyneet normit sitoivat erityisesti naisten lisäksi lapsia. Posetiivinkuuntelu (mainintoja noin vuosilta 1911-1917) on tästä hyvä esimerkki. Lapset eivăt saaneet tătă kauniina pitämäănsă musiikkia kuunnella, sillä "se oli syntiä ku lapset kuunteli ettei ne saanu semmosta syntiä tehä mutta aikaset sai kuunnella ja tehä sitä syntiä" (Y 9016:1,42).

Erityisesti naiset ottivat lämpimästi vastaan kansakoulunopettajien ja nuorisoseurojen perustamat kyläkuorot (Savelaan 1909, Raudaskylään 1917 ja 1924), ja kuorolaulusta muodostui myös rippikoulun käyneen nuorison kanssakäymisen muoto, jonka yhteisőkin hyväksyi. Myős tässä mielessä maaseudun nuoriso sivilisoitui - se pyrki "kotoisesta hämärästä" länsieurooppalaiseen valistukseen, kuten Esko Aaltonen asian ilmaisee kokoavassa artikkelissaan "Muutoksia maaseudun oloissa suuren murroksen ajoilta" (1951, 9). Ylivieskalaiset kyläkuorot esiintyivät äitienpäivillä, raittiusjuhlissa ja vaikkapa rautatien vihkiäisissä kohottavahenkisin lauluin sekä tekivät $\mathrm{mm}$. retkiä opettajan johdolla kesäisinä lauantai-iltoina karjamajoille. Musisointiretket luontoon sopivatkin sivilisoituneelle, luontoa ihannoivalle ihmistyypille paremmin kuin hämärässä, nokeavassa riihessä tanssaaminen (vrt. Bohman 1985, 192). Arvostettu kuorolaulu haluttiin kuitenkin ahdasmielisen heränneessä Raudaskylässä pitää tarkoin erossa tanssista ja pelkän tanssipaikan maineen saaneesta nuorisoseurasta, sillä "ne piti niin suurena syntinä sen ... tanssipaikan ja nuorisoseuran ... että sois ollu hirviä rikos jos laulukuoroki ois menny sinne laulamaan" (Y 9027:22).

\section{Lopuksi}

Tässä artikkelissa kuvasin kansanomaisten herätysliikkeiden protestanttisen etiikan vaikutuksia Pohjois-Pohjanmaalla sijaitsevan maaseutupaikkakunnan, Ylivieskan, talonpoikaiston ja työväestön musiikkiin. Ylivieska oli yksi myöhäisemmän herännäisyyden keskuksia, ja sitä mukaa kun liike levisi, ylivieskalaiset ryhtyivät karttamaan kaikkea synniksi näkemäänsä. Tanssi ja tanssisävelmien pelaaminen eivät olleet synneistä vähäisimpiä. Herännäisyys vaikutti käytännön tasolla voimakkaimmin talonpoikaiston ja heränneen alemman säätyläistön musisointiin ja tanssiin. "Kurttusten" eli suruttomien, jotka lukeutuivat useammin työväestöön kuin talonpoikiin, soittoa, laulua ja tanssia herätysliikkeet eivät saaneet loppumaan, mutta normitasolla tietynlaisen soiton ja laulun sekä kaiken tanssimisen synnillinen luonne oli 1900-luvun alussa jo sisäistetty. Niiden Suomen alueiden rahvaan musiikista puhuttaessa, joilla herännäisyys (miksei lestadiolaisuuskin) on vaikuttanut syvästi, ei sovi unohtaa protestanttista ihmistä, ja askeettisuuden vaatimusta, jolla hän kyllästi musiikin ja koko arkielämän. 


\section{Lähteet}

Aaltonen, Esko

1951 "Muutoksia maaseudun oloissa suuren murroksen ajoilta". Turun historiallinen arkisto XI. Turku.

Asplund, Johan

1983 Tid, rum, individ och kollektiv. Stockholm.

Bohman, Stefan

1985 Arbetarkultur och kultiverade arbetare. En studie av arbetarrörelsens musik. Nordiska museets handlingar 103. Arlöv.

Elias, Norbert

1978 The Civilizing Process. The History of Manners. Oxford.

Foucault, Michel

1980 Tarkkailla ja rangaista. Helsinki.

Frykman, Jonas et Löfgren, Orvar

1984 Den kultiverade människan. Skrifter utgivna av Etnologiska sällskapet i Lund. Stockholm.

Häggman, Ann-Mari

1976 "Ruotsalaisseutujen pelimannit ja soittimet". Paimensoittimista kisällilauluun, toim. Heikki Laitinen ja Simo Westerholm. Tutkielmia kansanmusiikista 1. Kansanmusiikki-instituutti. Alajärvi.

Jaatinen, Esko

1981 "Kirkko ja seurakunta". Ylivieskan kirja, toim. Aaro Harju ja Erkki Laitinen. Kokkola.

Järviluoma, Helmi

1986 Musiikki, liikkeet, hillikkeet. Talonpoikaiston ja työväestön musiikinviljely kolmessa Ylivieskan kylässä. Tampereen yliopiston kansanperinteen laitoksen moniste 11. Tampere.

Karisto, Antti, Takala, Pentti ja Haapola, Ilkka

1984 Elintaso, elämäntapa ja sosiaalipolitiikka. Aineistoa suomalaisen yhteiskunnan muutoksesta. Juva.

Leisiö, Timo

1986 "Cosc' suru suulla laulelen eli Yhden Ylpijän Pijan virsi". Kansanmusiikki 1.

Le Roy Ladurie, Emmanuel

1978 Montaillou. London.

Pentikäinen, Samuli

1981 "Herätysliikkeet Ylivieskassa". Ylivieskan kirja, toim. Aaro Harju ja Erkki Laitinen. Kokkola.

Päivärinta, Pietari

1885 Minä ja muut. Sakeus Pyöriän kertomuksia. Porvoo

1905 Siveellisyysoloista Pohjanmaalla rahvaan keskuudessa. Aikamme siveellisyyskysymyksiä 10 . Helsinki.

Renvall, Pentti

1951 "Piirteitä suomalaisen maaseudun heräämisestä". Turun historiallinen arkisto XI. Turku.

Sarje, Kimmo

1982 "Touhun lähteillä". Tiede ja edistys 1.

Sarmela, Matti

1969 Reciprocity Systems of the Rural Society in the Finnish-Karelian Culture Area. FF. communications 207. Helsinki.

Suolahti, Gunnar

1919 Suomen papisto 1600- ja 1700-luvuilla. Porvoo. 
Suolinna, Kirsti

1977 "Lestadiolaisuus ja agraarin väestön puolustusmekanismi".

Maailmankuvan muutos tutkimuskohteena, toim. Matti Kuusi, Risto

Weber, Max Alapuro ja Matti Klinge. Keuruu.

1980 Protestanttinen etiikka ja kapitalismin henki. Juva.

Vilkuna, Kustaa

1976 "Kalajokilaakson kasvonpiirteitä". Esipuhe teoksessa Vanhaa

Kalajokilaaksoa kuvien kertomana, toim. Soili Häkkilä. Kokkola.

Ylikangas, Heikki

1979 Körttiläiset tuomiolla. Massaoikeudenkäynnit heränneitä vastaan EteläPohjanmaalla 1830-1840 -lukujen taitteessa. Keuruu.

\section{Painamattomat lähteet}

Tampereen yliopiston kansanperinteen laitoksen yleiskokoelmat (Y):

Y 8428 Anni Somero, s. Savela, 3.1.1907. Haast. Helmi Järviluoma 1980.

Y 8437 Martta Juola, s. Säily, 11.11.1911. Haast. Helmi Järviluoma 1980.

Y 8474 Eino tuomikoski, s. 29.12.1905. Haast. Päivi Pasanen 1980.

Y 9014 Martta Säily, s. Isokoski, 17.8.1901. Haast. Helmi Järviluoma 1984.

Y 9015 Sama

Y 9016 Sama

Y 9019 Kohdat 1-26 August Juola, s. 11.12.1899 yhdessä Frans Isokosken, s. 2.1.1919 kanssa. Kohdat 27-29 Anna Mari Raudasoja, s. 26.6.1896. Haast. Helmi Järviluoma 1984.

Y 9020 Mari Raudasoja ks. ed.

Y 9022 Kohdat 1-21 Suoma Säily, s. 12.10.1907. Kohdat 22-31 Joonas Säily, s.29.1.1917. Haast. Helmi Järviluoma 1984.

Y 9023 Joonas Säily, ks. ed.

Y 9026 Helga Viitala, s. Säily 31.5.1909. Haast. Helmi Järviluoma 1984.

Y 9027 Sama ja Adele Isokoski, s. 2.2.1905. Haast. Helmi Järviluoma 1984.

Y 9031 Anni Somero, s. Savela, 3.1.1907 yhdessä Arvo Someron, s. 1908, kanssa. Haast. Helmi Järviluoma 1984.

Y 9041 Senni Savela-Kananoja, s.28.9.1918. Haast. Helmi Järviluoma 1984.

Y 9042 Sama

Suomalaisen kirjallisuuden Seuran äänitearkisto (SKSä)

SKSä 117 Jemiina Säily, s. 16.11.1891, ja Jaakko Säily, s.1891. Haast. Annamaria Viljanen 1971.

SKSä 118 Sama

Suomalaisen Kirjallisuuden Seuran Kansanrunousarkisto (SKSK)

Vilpula, Vilhelm. Ylivieska, Haapavesi. b)89. 1938.

Ylitalo, Mikko. "Kertomus Ylivieskan vanhoista seurustelu- ja häätavoista."

Käsikirjoitus E 81. Ei vuosilukua, muut samassa niteessä vuodelta 1928. 


\section{Summary}

The protestant ethic and the musical culture of the peasants and workers in the Ylivieska region

This article deals with the Protestant ethic and the musical culture of peasants and workers in a country parish in Northern Ostrobotnia during the first thirty years of this century. The writer assumes that the musical culture of the inhabitants of Ylivieska was strongly affected by the Protestant ethic of the revivalist movements, which had actively operated in the region ever since the 1830's. At that time Ylivieska was one of the centres of late Pietism, and as the movement gradually consolidated its position the ordinary people of Ylivieska started to avoid everything they considered a sin. Since the Pietists thought that wasting time was the most serious of the sins the article is also concerned with the changes in the concept of time amongst the common people.

Pietism worked on public opinion, turned it against amusements and restrained music making. It mainly affected the music of the peasants and lower middle class people. Profane people (suruttomat), such as workers, did not stop their playing, singing and dancing. Yet, they had also adopted the idea of music as a sin. For example playing the accordion was considered a serious sin under all conditions, while violinists could almost freely play other kinds of music except for dance tunes. Dancing was thought to be dangerous. Before, country weddings had been most impressive rituals in which dancing had played an important role. However, in the beginning of this century almost all peasants were already members of the revivalist movements and had stopped dancing at their weddings. Especially women and children had to obey the norms connected with music strictly. Interestingly enough, the new emerging forms of music composed or refined by professionals and introduced by the civilized bourgeoisie had a favourable reception. As regards the music of common people in those regions in which the Pietist revivalist movements operated, we should not underestimate the extent to which an ascetic Protestantism affected the musical culture and the whole of everyday life. 